\title{
Características da variante moçambicana da língua portuguesa com base na análise morfossintática dos diálogos presentes nos romances e contos de Mia Couto
}

\author{
Characteristics of Mozambican Portuguese based \\ on morphosyntactic analysis of dialogues in novels \\ and stories by Mia Couto
}

\author{
Sylwia Mikołajczak \\ Universidade Adam Mickiewicz \\ era104@poczta.onet.pl
}

\begin{abstract}
Portuguese is a native language of only a handful of people in Mozambique. However, it successfully plays the role of a common language of communication in the field of politics and economics. At the same time, it is a determinant of social status and, in the world of literature, it gives one the opportunity to break through to the readers around the Globe. Portuguese in Mozambique presents many differences from the European standard, and the specific characteristics of this variant can be found in the texts of Mia Couto. The purpose of this article is to present the differences between the variant of Mozambique and the European model of Portuguese, mainly in the field of morphosyntax, observed in the texts of Mia Couto. The marked differences can be seen, among others, in the use of prepositions, order of pronominal elements, in the structure of periphrastic and passive constructions, and the selection of verbal arguments. The features are highly repetitive, but at the same time, they occur quite irregularly, together with the structures accepted by the standard. It is, therefore, difficult to speak of a systematic language variant, but surely it is on its way to be established.
\end{abstract}

Keywords: Mozambican Portuguese, language differences, comparative syntax 
Isso tem de ser visto do ponto de vista de que Moçambique percebia que o português de Portugal servia, mas não bastava. Nós precisávamos introduzir nesse português uma marca de mudança, de identidade própria. É muito complicado fazer na língua do outro uma afirmação de nós próprios ${ }^{1}$.

\section{INTRODUÇÃO}

Independentemente do grau de espiritualidade que o nosso pensamento sobre a literatura possa alcançar, não podemos negar que a sua matéria básica é a língua. É ela que lhe dá o seu conteúdo, a sua cor, o seu caráter e a sua dimensão estética. As obras literárias de Mia Couto estão inseridas num panorama cultural-linguístico extremamente diversificado e complexo. Ainda mais, é importante enfatizar que o autor cria e recria o seu próprio estilo de linguagem, inventa palavras, usando diferentes processos de formação lexical. Bem como, utiliza o léxico e estruturas de diferentes partes de Moçambique na tentativa de refletir a originalidade da variedade local, mas também a originalidade da sua expressão literária.

O nosso objetivo foi encontrar características típicas e reais da variedade do Português de Moçambique ao nível morfossintático, provenientes de obras selecionadas de Mia Couto, embora estejamos conscientes que o material da pesquisa é, em grande parte, fruto da expressividade e criatividade individual do autor. O ponto de referência para a nossa comparação é o padrão europeu da língua portuguesa, o mesmo que o autor combina com os elementos provenientes das línguas bantu. Devido ao facto de analisarmos textos literários, concentrar-nos-emos especialmente nos elementos do nível morfossintático e, em menor escala, na esfera lexical ${ }^{2}$, omitindo o aspeto fonético da língua, porquanto é óbvia a dificuldade de o analisarmos nestas condições. Os exemplos que ilustram os fenómenos selecionados provêm de três romances e de duas colectâneas de contos de Mia Couto, principalmente nos diálogos das obras, porquanto seria nesses que o autor tentaria transmitir a especificidade da língua que é usada diariamente em Moçambique.

${ }^{1}$ „Patrząc z perspektywy Mozambiku, język portugalski z Portugalii nadawał się, ale nie wystarczał. Zaistniała potrzeba zmiany, wprowadzenia naszej własnej tożsamości. Trudno jest poprzez język obcych wyrazić siebie" (trad. própria), afirmação de Mia Couto retirada da entrevista: "O grande crime do racismo é que anula, em nome da raça, o indivíduo", conduzida por Letícia Duarte para o jornal „Zero Hora”, Porto Alegre, Brazil, 07.09.2014.

${ }^{2}$ Mia Couto intruduz nos seus textos elementos lexicais de diferentes línguas de Moçambique. Nas obras analisadas apareceram, entre outras, as palavras: moluene (do ronga, criança abandonada, sem abrigo), suca! (do changana, larga-te!), babaleze (do tsonga, ressaca), mezungo (do nianja, um branco), mulungo (do ronga, um branco), ngoma (tambor). Existe também um grupo de palavras introduzidas nas línguas africanas através do inglês, penetrando posteriormente na variante do Português de Moçambique, p. ex.: xitimela - comboio (do ing. steamer), bacecola - bicicleta (do ing. bicycle), Quissimusse Natal (do ing. Christmas), masuiti - doce (do ing. sweet). 
No entanto, antes de prosseguirmos à análise dos exemplos, seria importante apresentar os factos que contribuiram para a situação atual do Português em Moçambique.

\section{SITUAÇÃO DO PORTUGUÊS EM MOÇAMBIQUE}

Moçambique, um país de extensa área geográfica, é habitado por muitos grupos étnicos que se comunicam diariamente em mais de vinte línguas, a maioria delas provenientes da família das línguas bantu, entre as quais constam línguas como o macua, chimaconde, tsonga, copi, nhanja e sena. Estas constituem o grupo das principais línguas usadas pela maioria da população dessa área geográfica. "A maioria destas línguas são internacionais, quer dizer, são faladas também em países vizinhos de Moçambique. Isso significa que as fronteiras linguísticas são diferentes das fronteiras políticas" (Timbane, 2013).

Para a esmagadora maioria dos moçambicanos, mais de 7 milhões, o Português é a sua segunda língua, e apenas cerca de 10\% usam-na como L1. Segundo os dados publicados nas listas da https://www.ethnologue.com/country/MZ/languages ${ }^{3}$, o número de falantes de português chegou aos 10.250 .000 em 2016, isto é, 36\% de toda a população. Este facto deve-se provavelmente ao fortalecimento da posição da língua de Camões após o ano de 1975, onde foi reconhecida como língua oficial e posteriormente constitucionalizada em 2004, bem como à sua propagação no ensino geral. Atualmente, o Português é a única língua oficial, a principal língua dos meios de comunicação e a língua em que a literatura é criada neste país (Hlibowicka-Węglarz, 2003). Importa igualmente acrescentar que a percentagem de falantes desse idioma varia dependendo da região, assim como do grau de educação e sexo dos falantes. Em Maputo, $86 \%$ falam português, enquanto a província da capital é representada por $68 \%$ (Gonçalves, 2000). O número diminui à medida que nos afastamos da capital. Tal distribuição percentual é condicionada, em grande parte, pelo facto de que a faixa mais jovem da sociedade, em particular o sexo masculino, profissionalmente ativos, fala português em contextos onde a estrutura económica o favorece, ou seja, em grandes centros urbanos. O papel da língua portuguesa está, portanto, refletido nas perspetivas económicas proporcionadas pelo conhecimento da língua, porquanto é ela um fator que possibilita a "abertura ao mundo", contactos internacionais, desenvolvimento da carreira, etc.

Deve ser acrescentado que o Português, enquanto vestígio infame do passado colonial, teria provavelmente desaparecido do mapa linguístico de Moçambique se não fosse ela a língua mais difundida no país, funcionando com sucesso como ferramenta para a comunicação entre diferentes grupos étnicos a nível nacional.

\footnotetext{
${ }^{3}$ Data da consulta 10.04.2019.
} 
Outro fator que permitiu a manutenção da viabilidade da língua foi a presença dos portugueses, cujos primeiros representantes chegaram a Moçambique nos finais do século XV, juntamente com a expedição de Vasco da Gama. A partir desse momento, a língua portuguesa começa a marcar a sua presença enquanto língua dos colonizadores (o superstrato), tornando-se a ferramenta básica de comunicação com a população indígena. No século XVIII, a língua portuguesa começa a coexistir com outras línguas presentes nessas áreas, mas um século depois a sua posição enfraquece significativamente.

O início do século XX foi de significativa importância para a presença da língua portuguesa em Moçambique. Em 1918 terminaram as atividades militares dos portugueses, o que permitiu a criação de relações sociopolíticas mais amistosas que favoreceriam uma melhor receção da língua nas colónias. Em 1930 foi assinado o Ato Colonial, que regulamentou a situação política entre Portugal e a colónia moçambicana, concedendo-lhe autonomia limitada. Nesse mesmo ano é estipulado o acesso gratuito à educação em português. Lentamente, o português torna-se a língua de estratos sociais melhor educados, dos meios literários e dos serviços oficiais. Prova disso são as revistas literárias "O Africano" e "O Brado", publicadas em português. Adicionalmente, chegam a Moçambique nos anos 50 os novos colonos portugueses, em números tais que, nos anos 60 do século $\mathrm{XX}$, atingem os 60000 , facto este que se reveste de grande importância para o fortalecimento da língua portuguesa.

Depois de 1975, a língua portuguesa enquanto legado colonial torna-se fator positivo e valorizador, influindo numa melhoria do estatuto socioeconómico. No contexto literário, a língua portuguesa permite uma maior expansão no mundo e, concomitantemente, um maior alcance de público leitor. Esse é um factor não desconsiderado por autores como Mia Couto. Por outro lado, o facto de se ter tornado a língua de um grupo minoritário, mais educado e economicamente orientado, leva também à exclusão de uma maioria que não fala português e que tem um acesso bastante limitado à educação, ao avanço social e, consequentemente, à possibilidade de decidir sobre o futuro do país ${ }^{4}$.

A situação do contacto interlingual na realidade moçambicana onde quase metade da população completou apenas o primeiro nível de ensino e a percentagem de analfabetos continua alta $^{5}$, é uma questão muito complexa. O acesso ao ensino da língua portuguesa continua limitado para a maioria de pessoas.

\footnotetext{
${ }^{4}$ Esse problema foi discutido na entrevista com Eliseu Mabasso, linguista moçambicano, publicada no jornal Savana de 27 de junho de 2014.

${ }^{5}$ De acordo com os dados do Instituto Nacional de Estatística (2015, p. 5-21), dos cerca de 25.041.922 de habitantes, 49,9\% (taxa de analfabetismo) não sabem ler nem escrever.
} 


\section{PORTUGUÊS COMO LÍNGUA "DA MOÇAMBICANIDADE”}

Embora seja difícil tratar o PM como uma língua separada, há elementos de cultura, ou melhor, de culturas locais, refletidos nela. Segundo Mia Couto "O idioma português não é a língua dos moçambicanos. Mas, em contrapartida, ela é a língua da moçambicanidade", e ainda: "Porém, é já um português outro, uma língua afeiçoada à cor e à textura da nação moçambicana".

Embora seja a língua oficial de Moçambique e ainda que esteja em franco crescimento, a variante do português de Moçambique apresenta características específicas que são reconhecíveis em comparação com outras variantes do português. Importa também mencionar que o PM exibe muitas características em comum com a língua portuguesa de Angola (Hlibowicka-Węglarz, 2003, p. 43), o que indicia uma influência significativa das línguas bantu em ambas as variantes, embora a situação sociopolítica também tenha desempenhado um papel fulcral. Tanto o Português de Moçambique como o Português de Angola perderam / perdem a «matéria gramatical e lexical» da língua-alvo, caminhando de forma acelerada para uma nativização (Timbane, 2016, p. 11).

A isto vale a pena acrescentar que, ao contrário de Cabo Verde ou de São Tomé e Príncipe, as variantes de Moçambique e de Angola não deram lugar nem à crioulização nem à pidginização das línguas. Isto deve-se à forte posição e extensão de línguas locais, ao isolamento da província e ao papel importante de capatazes e missionários que desempenhavam os papéis de intermediários ou intérpretes na comunicação com a população local (Pereira, 2006, p. 68).

No contexto da realidade multilingue de Moçambique, é óbvio que as línguas irão influenciar-se e moldar-se mutuamente. $\mathrm{O}$ contacto será propício para o surgimento de novas formas linguísticas, através de um número significativo de empréstimos, interferências e composições. Embora muitos fenómenos linguísticos recorrentes sejam perceptíveis ao nível da fonética, do léxico ou da sintaxe, e que constituam uma característica distintiva dessa variante da língua portuguesa, é difícil falar de uma variante padronizada. Alguns dos fenómenos que ocorrem são pontuais, irregulares e instáveis. Além das formas que se desviam do padrão europeu, existem outras, do mesmo fenómeno, que seguem esse mesmo padrão.

Para além disto, a normatização do PM constitui um aspecto prioritário e pertinente para a realização de qualquer trabalho relacionado com a gramática do PM. Assim, poder-se-á dirimir as inconveniências de se estudar o PM com base no PE, estudos que acabam sendo somente de caráter contrastivo (Gonçalves et al., 1998; Gonçalves, 1998), focalizando essencialmente a dicotomia "errado / certo" (Nhatuve, 2017, p. 2).

\footnotetext{
${ }^{6}$ Retirado do texto publicado na antologia galega "Do músculo da boca", ed. Encontro Galego no Mundo, Santiago de Compostela 2001.
} 
Conforme expresso por Zamparoni (2009) os moçambicanos nunca falaram a norma-padrão europeia. Desde o início aparecem nela as características que permitem encontrar elementos de identidade cultural bem incorporados, que procuram expressar-se através de uma língua alheia que não lhes pertencia antes, porquanto “(...) no Português falado pelas camadas mais escolarizadas (...) ocorrem com regularidade fenómenos não detetáveis nem na variedade europeia nem na brasileira (...)" (Duarte, 2000, p. 22).

Muitos linguistas corroboram a opinião de que o PM é uma variante específica do português, adaptada com base nas culturas africanas, com manifestações de numerosas influências das línguas bantu (Vilela, 1995; Lopes, Sitoe e Nhamuende, 2013).

\section{AS CARACTERÍSTICAS MORFOSSINTÁTICAS DO PM ENCONTRA- DAS NAS OBRAS DE MIA COUTO}

As diferenças entre o PE e o PM são visíveis em vários níveis da estrutura da língua, tais como na fonética, na fonologia, na morfossintaxe e na semântica. Apresentaremos a nossa lista de fenómenos linguísticos característicos, começando pelos traços sintáticos, nomeadamente pelos verbos locativos, isto é, aqueles que indicam relações no espaço e se referem a um lugar que define os argumentos do verbo. $\mathrm{O}$ indicador e elemento de ligação dessa relação é a preposição que acompanha o verbo.

\subsection{Preposição em com verbos de movimento}

A preposição em sugere uma posição estática, corresponde semanticamente ao conceito de "fechamento" num local. No entanto, encontramos exemplos onde se combina a preposição em com verbos semanticamente associados ao movimento numa direção específica.

1/ É que vou voltar na minha terra (Cronicando, A lição do aprendiz, p. 72).

Tal aplicação da preposição em está presente na variante coloquial do português do Brasil, sendo também bastante comum nas produções orais de estudantes polacos que aprendem português como L3 (com L2 espanhol) (Mikołajczak, 2018), especialmente na fase inicial de aprendizagem, onde encontramos com frequência enunciados como:

2/ Em Julho fui na minha casa familiar (Mikołajczak, 2018, p. 97).

No padrão europeu, para a função direcional relacionada ao movimento, usamos geralmente as preposições $a$ ou para. A aparente confusão no momento de escolher 
a preposição em construções verbais é um fenómeno comum em Moçambique. Isso pode ser explicado pelo facto de que são os substantivos e os verbos os elementos mais frequentes entre as partes do discurso no nível morfológico, porquanto carregam o significado semântico mais importante. As preposições são um elemento de cariz gramatical, embora não desprovido de significado, e desempenham funções sintáticas que não se destacam claramente na estrutura da frase, pelo que são frequentemente omitidas ou confundidas. Além disso, tanto a preposição locativa usada na ideia de movimento, como a função estática são proporcionadas pela mesma preposição nas línguas bantu (Hlibowicka-Węglarz, 2003, p. 38), o que contribui para a convergência das formas preposicionais em e $a$ no PM.

Os linguistas, Perpétua Gonçalves e Feliciano Chimbutane (2002-2003) descrevem muitos casos do uso de preposições que diferem da variante do PE. A sua pesquisa, realizada desde 1998, expõe diferenças na escolha das categorias preposicionais, juntamente com a mudança no comportamento dos complementos de verbos de movimento, tais como: ir, chegar, etc.

\subsection{Preposição $e m+\mathrm{SN}$ de lugar}

Uma característica adicional do uso de preposições é ilustrada nos exemplos abaixo:

3/ No meu quarto é grande (PE: O meu quarto é grande).

4/ Conhece na cidade (PE: Conhece a cidade).

A presença da preposição, seja com o sujeito ou com o complemento direto, é, em ambos os casos, sintaticamente desnecessária. A preposição em perde a sua função locativa, tornando-se parte do grupo nominal, mais frequentemente com uma função enfática do que sintática. É possível relacionar a origem desse traço com o sistema existente em certas línguas bantu, onde os prefixos surgem como expoentes de várias funções gramaticais (p.ex. marcadores do objeto ou classes de substantivos, entre outros).

Verificam-se também exemplos da ocorrência da preposição $\mathrm{em}$ na função de determinação de origem ou local de partida:

5/ Tinha saído na sala (PE: Tinha saído da sala).

6/ Parti no Maputo (PE: Parti de Maputo).

Aqui, a preposição em substitui de, que é a usada na variante europeia. Em geral, observamos na variante do PM o uso mais comum da preposição em. Por vezes, no entanto, certas preposições, incluindo em, são omissas ou substituídas por outras de caráter normativo: 
3.3. Comportamento morfossintático de verbos preposicionais em frases relativas

Normalmente, a ordem das preposições é sujeita a um verbo, que é refletido na sua posição pré-verbal:

7/ O conceito geral com que o tema está relacionado.

8/ A rapariga de quem gosto mudou-se.

No PM a ordem de preposições é frequentemente alterada:

9/ A rapariga que gosto dela mudou-se.

Diversos trabalhos mostram que o PM privilegia a estratégia resuntiva em relativos de vários tipos de objetos, seja diretos, oblíquos ou indiretos (e.g. Chimbutante, 1996; Brito, 2001; Hagemeijer, 2016).

3.4. Função de complemento direto e indireto de pronomes pessoais

Neste ponto, verificamos vários exemplos onde a função de complemento direto dos pronomes é substituída por um complemento indireto:

10/...ela pediu para lhe ver assim que você chegasse (Um rio chamado tempo, uma casa chamada terra, p. 30).

11/ Matei-lhes, satanhocos (Cronicando, p. 27).

12/ Quero-lhe é mais molhada que a chuva (Fio das missangas, p. 44).

13/ Sim, mataram-lhe (Um rio chamado tempo, uma casa chamada terra, p. 60).

14/ Eu nunca mais quero ver-lhe (O último voo do flamingo, p. 199).

O verbo matar é transitivo com complemento direto, que aqui está substituído pelo dativo. A combinação do verbo com a forma pronominal do complemento direto exige transformações apropriadas (redução do $r$ no infinitivo, acréscimo do acento gráfico, etc.), o que constitui um dos aspectos mais difíceis da estrutura morfogramatical da língua portuguesa. Considerando o facto de que o uso de uma língua tende para a sua simplificação formal e que os desvios da norma do PE nas combinações verbo-pronominais são alguns dos mais recorrentes, entende-se que isso aconteça nestas variantes do PE, dadas as naturais diferenças na instrução gramatical dos seus falantes. Além disso, o facto de que nas línguas bantu a mesma forma é usada para indicar ambos os complementos, isso contribuirá ainda mais para a mistura dessas formas no PM. 


\subsection{Passivas Dativas}

Outro fenómeno sintático interessante é o uso repetido de construções passivas com dativo. Vejamos alguns exemplos retirados de textos de Mia Couto:

15/ Já disse: Esses livros fui dado (Cronicando, Lénine na cabeceira, p. 18).

16/ Este lenço fui dada na cidade (Um rio chamado tempo, uma casa chamada terra, p. 19).

Esta estrutura passiva específica consiste na transformação do grupo nominal, com função complementar, no sujeito na forma passiva. Os motivos de tal transformação estrutural podem ser derivados da influência da construção equivalente do inglês: I was given a book, mas o mais provável é ser mais um caso de transferência das línguas bantu (Vilela, 1999, p. 189). Esse tipo de construção é considerado agramático no PE (Firmino, 2008, p. 18). Para transformar essa construção numa aceitável no PE, seria necessário utilizar o pronome na forma de complemento indireto. Então, o substantivo no complemento direto tornar-se-ia o sujeito da frase, e não (como no exemplo 16) o pronome pessoal eu:

\section{7/ Este lenço foi dado a mim (PE).}

O lapso no uso de tal construção deve-se, em princípio, ao facto de que o Português Europeu não permite ao complemento indireto a função de sujeito, quer dizer: *Eu fui dada..., o que é permitido nas construções do inglês:

18/I was given a present.

Esta tendência leva também à omissão frequente da preposição $a$, que é obrigatória no PE, antes de complementos indiretos.

O seguinte caso de uso de voz passiva ilustra mais uma característica do uso preposicional, desta vez com a preposição com.

19/ Foste dado com quem? (Cronicando, Lénine na cabeceira, p. 19).

Provavelmente, devido à influência da língua tsonga e de outras línguas bantu, em vez da preposição por, que geralmente precede o agente em construções passivas, surge a preposição com, que transmite essencialmente a relação de coparticipação. Isso deve-se ao facto de que, nas línguas bantu, ambos os significados são expressos pela mesma preposição.

\subsection{Omissão de preposições em construções perifrásticas}

Permitam-nos explorar um pouco mais o tema do uso de preposições. Desta vez, trata-se da sua não utilização em construções perifrásticas, em particular na construção de estar a + infinitivo (fazer alguma coisa no imediato, ou estar em vias de fazer algo): 
Encontramos muitos casos nos quais a preposição $a$ é omissa:

20/ Estão (-) ver? (Fio das Missangas, p. 58).

21/...estou (-) escutar o azul (Um rio chamado tempo, uma casa chamada terra, p. 20).

22/ Eh, pá, esta mesa está (-) diminuir! (Contos do nascer da terra, p. 13).

23/ Vocês não estão (-) ver? (Contos do nascer da terra, p. 14).

24/ Eu estava (-) sonhar pássaros (Contos do nascer da terra, p. 39).

25/ Ando (-) aprender a língua dos pássaros (O último voo do flamingo, p. 164).

Ao mesmo tempo, utilizam-se variantes da mesma construção perifrástica que são consideradas corretas no PE:

26/ Estou falando de terra, parece que está moribundando (Contos do nascer da terra, p. 156).

$27 /$... de que cerimónia estamos a falar? (Um rio chamado tempo, uma casa chamada terra, p. 33).

O facto de tais formas aparecerem em paralelo pode ser explicado por uma certa inconsistência ou negligência gramatical, verificada ao nível da língua falada, refletida nos diálogos das obras de Mia Couto.

A situação é similar no que diz respeito à manutenção da concordância de número e género entre componentes de frases.

\subsection{Ordem de pronomes}

Nos diálogos das obras de Mia Couto verificam-se numerosos casos de posicionamento de pronomes antes de verbos, como no caso da variante brasileira do português.

28/ Me leia a carta (Cronicando, Carta, p. 9).

29/ Me vens ler o meu filho? (Cronicando, Carta, p. 11).

30/ Me está a entender? ( $O$ último voo do flamingo, p. 49).

31/ Mas me diga uma coisa? (Contos do nascer da terra, p. 174).

Em geral, a próclise aparece no PM muito mais frequentemente que no padrão europeu.

3.8. Desvios da norma em termos de concordância de número e género

32/ É que já estamos a gastar muita pilhas (O último voo do flamingo, p. 86).

Desconcordâncias desse tipo são frequentemente observadas não só em crioulos, mas também no registo coloquial de linguagem. Isso pode ser explicado pelo facto 
de que a concordância é expressa em línguas bantu por meio de ajustes das formas gramaticais dentro de um grupo nominal, usando para isso prefixos correspondentes a uma determinada classe de substantivos. Assim, o que muda é o início das palavras e não o seu final, como no caso do português.

\subsection{Uso específico e omissão de artigo}

No corpus analisado por Gonçalves (1997, p. 57), cerca de $80 \%$ dos desvios está relacionado com a tendência de omitir ou usar incorretamente os artigos. Temos observado um número significativo de exemplos nos quais o artigo se encontra omitido. A sua função determinante parece de pouca importância para os falantes, como se o contexto fosse mais importante do que o valor gramatical desse elemento. $\mathrm{O}$ conceito de artigo está igualmente presente nas línguas bantu, mas com a diferença de que existem tantos artigos como classes de substantivos, em alguns casos mais de 20. Desta forma, o artigo tem um maior "cargo semântico". No entanto, o posicionamento do artigo é diferente, uma vez que surge após o substantivo. As diferenças mencionadas podem afetar o uso desses determinantes no PM.

33/ Durmo aqui, ( $\theta$ ) mato é lugar dos cabritos (Cronicando, A Sombra sentada, p. 15).

Há também casos de uso de artigos considerado inaceitável no PE. Neste sentido, podem ser detetados casos de duplicação de elementos com função determinante, por vezes com o sentido oposto, como no exemplo 36:

34/ Não podemos, há o morto... (Um rio chamado tempo, uma casa chamada terra, p. 112).

35/ Por que vieste nessa minha casa? (Cronicando, Carta, p. 11).

36/ Quero dar-te esta uma coisa (Cronicando, A Prenda do viajante, p. 91).

37/ Qualquer uma coisa vai acontecer! (Cronicando, A Velha e a Aranha, p. 34).

Isso pode ser devido ao facto de haver muita mais variedade em formas e posições de determinantes em línguas bantu e de suas ocorrências duplificadas. No entanto, em algumas vezes, a duplificação de determinantes pode ser explicada por seu maior cargo emotivo.

\subsection{Formas reflexivas e pronominais de verbos}

Nos diálogos analisados encontrámos verbos na forma reflexiva ou pronominal, que não costumam ser reflexivos nem pronominais nas formas do PE: 
38/ Ela não pode continuar-se vizinha da água (Cronicando, O Jardim marinho, p. 55).

$\mathrm{O}$ verbo continuar pode ser pronominal no $\mathrm{PE}$, mas não no contexto aplicado ao exemplo 38. Continuar-se tem o significado de persistir-se ou prolongar-se, noutros casos aparece sem pronome.

Outro exemplo mostra um fenómeno parecido:

39/ Você se acredita nisso? ( $O$ último voo do flamingo, p. 56).

No PE é possível a utilização de acreditar-se, mas num sentido diferente, nomeadamente na perspetiva de "tornar(-se) digno de confiança e consideração" ou "considerar-se". No sentido de crer, aquele não possui forma pronomina.

Outros exemplos de desvios de formas reflexivas ou pronominais:

40/ Às vezes tenho-me pena (Cronicando, Pela gravata morre o tímido, p. 85).

41/ Essa mulher que não se chegue (Um rio chamado tempo, uma casa chamada terra, p. 22).

42/ Faço-me falta, sem você, meu filho (Um rio chamado tempo, uma casa chamada terra, p. 25).

Parece-nos que nos exemplos 40 e 42 os pronomes usados indicam uma função mais emotiva do que reflexiva. No entanto, perante os exemplos apresentados em cima, é interessante que outros autores (Gonçalves, 1996, p. 317; Hagemeijer, 2016, p. 59) indicam uma forte tendência para supressão de pronomes reflexos no PM.

\subsection{Uso de verbos intransitivos em lugar de transitivos}

Concentremo-nos agora por um momento no assunto do uso específico de verbos.

43/ Por obrigação lhe nasceu ofilho...

(Contos do nascer da terra, O General infanciado, p. 173).

$\mathrm{O}$ verbo nascer é um verbo intransitivo no $\mathrm{PE}$, que corresponde à expressão "dar à luz" no sentido transitivo. No entanto, na variante do PM, muitas vezes funciona como um verbo com o objeto direto (o filho - no ex. 43).

\subsection{Uso do imperativo}

Nalguns casos, as formas do modo imperativo, seja afirmativo ou negativo, formal ou informal, têm a mesma forma verbal:

44/ Não chora, mãe (Cronicando, O Jardim marinho, p. 54). 
No exemplo acima, a forma negativa do verbo no modo imperativo deveria tomar a forma de chore ou chores, enquanto retém a mesma forma que no caso da afirmativa do imperativo. Também na variante do português do Brasil se verificam exemplos desta natureza.

\subsection{Clivadas}

Este tipo de estrutura é usado para enfatizar a informação importante na frase. Exemplo disso é a seguinte construção enfática sintática, usada na variante europeia da língua portuguesa:

45/ Eu como é as maçãs.

Contudo, é interessante verificar que no PM é possível encontrar as mesmas estruturas adicionalmente reforçadas com o advérbio só:

46/ Só eu tenho medo é do tempo... (Contos do nascer da terra, p. 28).

Ou então, surgindo este sozinho como um elemento enfático:

47/ Eu quero só ficar com Cristovinho (Contos do nascer da terra, p. 164).

O mesmo uso do advérbio só é igualmente comum na variante do português de Angola.

3.14. Reduplicação de elementos da frase

A reduplicação de palavras serve para reforçar determinados elementos ou ideias da frase.

48/ O gajo é mestre de preguiça, lhe conheço desde-desde (Contos do nascer da terra, p. 174).

Esta forma de reforço enfático é típica nas variantes africanas do português, onde surge igualmente enquanto ferramenta morfológica para formar o plural de substantivos. Importa referir que o PE também recorre, ainda que pontualmente, ao uso do mesmo procedimento de formação de palavras.

\subsection{Formas do plural}

O último traço morfológico que iremos abordar é uso do plural em advérbios. Apresentam-no os seguintes exemplos: 
49/ Não tem medo que eu fique por lás, nunca mais voltado? (Contos do nascer da terra, p. 62).

50/ E me dá um medo de me sozinhar por esses aís (Contos do nascer da terra, p. 157).

Este fenómeno pode ser considerado um caso de derivação imprópria, por meio de que um termo, originalmente advérbio, pode agregar o morfema do plural e apresentar-se como substantivo.

\section{CONSIDERAÇÕES FINAIS}

A sociedade de Moçambique encontra-se dividida em vários grupos linguísticos. As línguas africanas são línguas nativas para a maioria dos seus habitantes, pelo que constituem um referente da sua identidade e da sua cultura. A língua portuguesa funciona como uma segunda língua usada em contextos formais e oficiais. É evidente que numa realidade multilingue as línguas irão influenciar-se umas às outras. As características das mudanças que ocorrem na língua portuguesa pós-colonial são marcadas por muitas influências linguísticas, cognitivas e psicológicas, motivadas cultural e historicamente. Tais influências são visíveis ao nível morfossintático e lexical do PM. Os exemplos retirados de contos e romances de Mia Couto analisados no corpus deste estudo mostraram as seguintes características da variante da língua portuguesa em Moçambique, e evidenciaram a sua regularidade: uso de preposições em, $a$, de, com; ordem de pronomes, uso do artigo, falta de concordância, estruturas passivas e enfáticas específicas.

Todos os fenómenos apresentam um certo desvio da norma padronizada, que é influenciada não apenas pelas línguas indígenas da população de Moçambique, mas também pelo baixo nível de educação institucionalizada. Os exemplos acima mencionados não permitem provar a existência de um "padrão" separado do português em Moçambique, mas apontam para as suas características específicas e para uma manifestação clara da nacionalização da língua, o que poderá resultar na formação de uma futura variedade linguística no mundo da Lusofonia. Os traços que acabámos de apresentar podem servir de prova das mudanças contínuas que ocorrem no $\mathrm{PM}$, mudanças essas que fazem uma variedade línguistica exclusiva em progresso. 


\section{BIBLIOGRAFIA}

Brito, A.M. (2001). Relativas de genitivo no português europeu e no português de Moçambique, In. C. Nunes Correia, A. Gonçalves (Eds.), Actas do XVI Encontro Nacional da APL (pp. 115-129). Lisboa: APL.

Duarte, I. (2000). Língua Portuguesa: instrumentos de análise. Lisboa: Universidade Aberta.

Firmino, G. (2008). A situação do português no contexto multilingue de Moçambique. Maputo: Universidade Eduardo Mondlade.

Gonçalves, P. (1996). Aspectos da sintaxe do português de Moçambique. In I. Hub Faria et al. (Eds.), Introdução à linguística geral e portuguesa (pp. 313-322). Lisboa: Caminho.

Gonçalves, P. (1997). Português de Moçambique. Uma variedade em formação. Maputo: Universidade Eduardo Mondlade.

Gonçalves, P. (2000). Dados para a história da língua portuguesa em Moçambique. Maputo, $<$ http://cvc.instituto-camoes.pt/hlp/geografia/portuguesmocambique.pdf $>$ (acesso: 20.05.2016).

Gonçalves, P., Chimbutante, F. (2002-2003). O papel das línguas bantu na génese do português de Moçambique: O comportamento sintático de constituintes locativos e direcionais. Maputo: Universidade Eduardo Mondlade.

Gonçalves, P. et al. (1998). Estruturas gramaticais do português: problemas e exercícios. Maputo INDE: Panorama do português oral de Maputo, 3, 36-139.

Hagemeijer, T. (2016). O português em contacto em África. In A.M. Martins, E. Carrilho (Eds.), Manual de Linguística Portuguesa (pp. 43-67). Berlin/Boston: De Gruyter.

Hlibowicka-Węglarz, B. (2003). Język portugalski w świecie. Lublin: Wydawnictwo UMCS.

Lopes, A.J., Sitoe, S.J., Nhamuende, P.J. (2013). Moçambicanismos: para um léxico de usos do português moçambicano. Luanda: Editora Letras.

Mikołajczak, S. (2018). Interferências entre o espanhol L2 e o português L3. Estudo qualitativo e quantitativo com foco em categorias funcionais. Poznań: Wydawnictwo Naukowe UAM.

Nhatuve, D. (2017). Reflexão sobre a normatização do português de moçambique. Florianópolis. Fórum Linguístico, 14 (2), 1997-2007.

Pereira, D. (2006). O essencial sobre a língua portuguesa: crioulos de base portuguesa. Lisboa: Caminho.

Timbane, A.A. (2013). A variação linguística e o ensino do português em Moçambique. Revista Confluências, 43 (2), 263-286.

Timbane, A.A. (2016). Que português se fala em Moçambique? Uma análise sociolinguística da variedade em uso. Vocábulo. Revista de Letras e Linguagens Midiáticas, 7, Ribeirão Preto.

Vilela, M. (1995). Ensino da língua portuguesa: léxico, dicionário, gramática. Coimbra: Almeida.

Vilela, M. (1999). A língua portuguesa em África: Tendências e factos. Africana Studia, 1, Edição da Fundação Eng. António de Almeida, Porto.

Zamparoni, V.D. (2009). Colonialismo, jornalismo, militância e apropriação da língua portuguesa. Moçambique nas décadas iniciais do século XX. In C. Galves, H. Garmes, F.R. Ribeiro (Eds.), África-Brasil: caminhos da língua portuguesa. Campinas-SP: Unicamp.

\section{Textos analisados no corpus}

Couto, M. (1991). Cronicando. Lisboa: Caminho.

Couto, M. (1997). Contos do Nascer da Terra. Lisboa: Caminho.

Couto, M. (2000). O último voo do flamingo. Lisboa: Caminho.

Couto, M. (2002). Um rio chamado tempo, uma casa chamada terra. Lisboa: Caminho.

Couto, M. (2004). O fio das missangas. Lisboa: Caminho. 